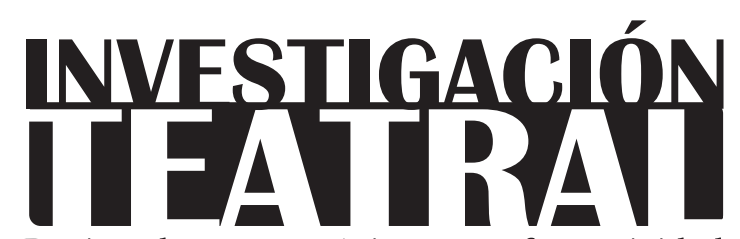

Revista de artes escénicas y performatividad

Vol. 9, Núm. 13

abril-septiembre 2018

Segunda época

ISSN impreso: 1665-8728

ISSN electrónico: 2594-0953

Universidad Veracruzana

\title{
El cuerpo del/la boxeador/a: danza y representación
}

\author{
Hortensia Moreno*
}
* Centro de Investigaciones y Estudios de Género, Universidad Nacional Autónoma de México, México. e-mail: hortensia_moreno@cieg.unam.mx

Recibido: 30 de agosto de 2017

Aceptado: 01 de diciembre de 2017 


\title{
El cuerpo del/la boxeador/a: danza y representación
}

\section{Resumen}

A partir del video Round en la sombra (2007), dirigido por Alfredo Salomón, reflexiono acerca de los recursos semióticos corporales de dos campos contrastantes: el boxeo y la danza. Trato de poner en contexto el poder de significación que se despliega en la exhibición del cuerpo semidesnudo en el cuadrilátero. Como coreografía cuidadosamente ritualizada, esta representación persigue la producción performativa de la masculinidad, en oposición a la que le servirá de referente y límite: la del cuerpo de la boxeadora como contradicción y reafirmación de la ofrenda escenificada en la pelea. Las prácticas corporales de estas dos disciplinas me sirven como pretexto para discutir la exclusión de las mujeres del campo deportivo.

Palabras clave: boxeo, danza, performatividad, performance, género, México.

\section{The Boxer's Body: Dance and Representation}

\begin{abstract}
Using Round en la sombra (2007), a video directed by Alfredo Salomón as a basis for discussion, I examine the semiotic bodily resources of two contrasting fields: boxing and dance. My intention is to contextualize the signifying power deployed in the exhibition of the half-naked body on the ring. In a carefully ritualized choreography, this representation contributes to the performative production of masculinity in opposition to that of the female boxer's body - its model and limit - which works as both contradiction and reaffirmation of the sacrifice staged at the fight. With the physical practice of these two disciplines in mind, I discuss the exclusion of women from the sports' field.
\end{abstract}

Keywords: box, dance, performativity, performance, gender, Mexico. 


\section{El cuerpo del/la boxeador/a: danza y representación}

\section{Preámbulo}

ound en la sombra (2007) fue filmado a partir de una idea de Patricia Camacho
Quintos, quien en 2007 publicó la novela Danza y box: bálsamo y herida. A pesar
de ser un producto derivado del trabajo literario, el video en sí mismo posee una alucinante capacidad expresiva. El ejercicio videográfico - tributario de una correcta apropiación del lenguaje cinematográfico- se organiza alrededor de la contraposición de dos tipos de técnicas corporales: por un lado, las deportivas (específicamente las del boxeo), y por el otro, las de la danza escénica contemporánea. El reto para Gilberto González, ${ }^{1}$ bailarín, es el de replicar la estructura visual de la locomoción pugilística; el reto para Dante Jardón, boxeador, es mostrar en el cuadrilátero esa misma estructura sin producir los efectos "reales" de la confrontación (o sea, sin noquear al bailarín).

${ }^{1}$ Gilberto González es un bailarín y coreógrafo muy particular, define su trabajo como danza-teatro del gesto, se ha entrenado con técnicas de danza contemporánea, pantomima y teatro. Ganó varios premios nacionales como bailarín y coreógrafo de la compañía Onírico danza-teatro del gesto y trabajó dos años en el Cirque du Soleil. Gloria Godínez (2018), especialista en teoría de la danza, cree que "la habilidad gestual con la que Gilberto ha decodificado o deconstruido el lenguaje del boxeo hasta convertirlo en una coreografía es especial, no cualquier bailarín podría haberlo hecho" y agrega que "gracias a la yuxtaposición de lenguajes inscritos en los cuerpos de bailarín y boxeador, así como a la edición de video y la música, Alfredo Salomón nos ofrece al final un híbrido video-danza-box muy interesante" (Godínez, conversación). 
La actuación profesional de esos dos cuerpos obedece a lógicas distintas, pero confluye en varios puntos. Se trata, en ambos casos, de cuerpos altamente especializados, resultado de largos procesos de aprendizaje donde han sido sometidos a disciplinas rigurosas, y cuyos rendimientos equivalen a niveles muy altos de destreza, fuerza, coordinación y resistencia. Uno de los puntos nodales de la práctica boxística es la organización de ese conjunto de coordinaciones motoras en función del ritmo. Entre los vínculos que pueden establecerse entre el boxeo y la danza está la idea de que "un boxeador necesita ser un buen bailarín", como la expresa, por ejemplo, el entrenador cubano Miguel Baro (cit. en Palma 15). Además, tanto el boxeo como la danza obedecen al marco social del espectáculo, es decir, se trata de prácticas escenificadas y, en esa medida, se puede afirmar que son performáticas. ${ }^{2}$ No obstante, el involucramiento del cuerpo como lugar específico de la representación nos obliga a dibujar una línea muy fina y porosa entre recursos semióticos (aquellos que se utilizan con la finalidad específica de significar) y actos materiales.

Dichos puntos de confluencia constituyen uno de los ejes de mi reflexión: en tanto se trata de dos disciplinas "diametralmente opuestas", el boxeo y la danza construirían cuerpos visiblemente distintos. Lo que el video muestra es la afinidad entre el cuerpo de un bailarín y el de un boxeador; afinidad que llega al extremo en que ambos se confunden y se vuelven prácticamente indistinguibles. ${ }^{3}$

Desde luego, esta confusión es artificial (y en esa medida performática). Se trata de dos especializaciones que no permiten que estos cuerpos "hagan lo mismo": el boxeador — con su nivel de preparación actual - sería incapaz de las precisiones de la danza contemporánea (por ejemplo, no podría girar y rodar con los pies descalzos como lo hace el bailarín). ${ }^{4}$ Por su parte, el bailarín es incapaz de propinar o de "absorber" un golpe como lo hace el boxeador. No obstante, a pesar de la apariencia de "ingravidez" propia de la danza, el cuerpo del bailarín

${ }^{2}$ Utilizo la noción de lo "performático" para distinguir, en el plano de la significación, los contenidos que se derivan de la práctica teatral de aquellos relacionados con el denominado "performance", pensado en sentido amplio como un lugar de representación cuya principal característica es su dimensión de acontecimiento, es decir, su carácter único e irrepetible, a pesar de ocurrir en el contexto de la sociedad y la cultura -lo cual media ese carácter pero no lo suprime-. Lo performático pertenece al ámbito de la representación escénica sin sujetarse de manera rígida a la normatividad de lo teatral, pero puede ser examinado a la luz de la reflexión acerca del performance (véase, por ejemplo, Schechner, Performance Studies; Prieto, "En torno a” y “iLucha libre!”; Slaughter y Moreno, Representación y fronteras).

${ }^{3}$ Se trata, por supuesto, de un boxeador de peso ligero; seguramente el símil deja de funcionar conforme nos acercamos a la constitución de un boxeador de peso completo.

${ }^{4}$ Una de las escenas del principio del video nos advierte de manera sutil acerca de esta diferencia: mientras que el boxeador se venda las manos, el bailarín se venda los pies. 
es equivalente en términos de fuerza o musculatura al del boxeador. Las semejanzas entre las dos disciplinas son relevantes en la medida en que se trata de maneras análogas de producción del cuerpo como materia prima tanto de la acción humana como de su representación, en un juego visual donde se evidencia la imposibilidad de separar estos dominios.

De manera particular, es dentro del marco social del espectáculo donde la diferencia entre "hacer" y "representar" se vuelve más difusa. ${ }^{5}$ El concepto de performatividad nos ayuda aquí en la medida en que lo extendamos del espacio de lo lingüístico al espacio de lo ritual, para lo cual hace falta insistir en que la separación abstracta entre lo lingüístico y lo concreto existencial sólo se da en términos conceptuales. La palabra sólo tiene existencia en el cuerpo y en la materialidad específica del contexto donde ese cuerpo existe; por lo tanto, la producción de sentido excede lo lingüístico en la medida en que hay procesos de semiosis completamente deslindables de la palabra: signos que residen en el cuerpo y recursos semióticos diferentes del cuerpo, pero que lo acompañan de una manera tan estrecha que resulta difícil distinguirlos de la corporalidad.

Por eso se puede afirmar que la performatividad no se reduce al lenguaje que actúa, sino que incluye a la acción que significa (Hollywood 256). La acción significativa implicada en la idea de ritual nos llama la atención sobre la performatividad de prácticas corporales que no son lingüísticas. He aquí una afinidad más entre el boxeo y la danza: se trata de dos disciplinas altamente ritualizadas donde los cuerpos se ofrecen a la mirada como ofrendas. ${ }^{6}$

\section{Cuerpo, género y boxeo}

Los estudios del deporte permiten abordar una amplia gama de temas relacionados con el cuerpo, el género y las relaciones sociales. ${ }^{7}$ Uno de los enfoques para este tipo de investigación es el semiótico, que busca dilucidar los mecanismos de significación

${ }^{5}$ En performances como el de la lucha libre, esta indistinción se vuelve más evidente: ¿hasta dónde está fingiendo un performer que se produce hemorragias en la cara para dramatizar el espectáculo?

${ }^{6}$ Para una reflexión más amplia sobre el ritual y la performatividad véase: Turner, The Anthropology; Yébenes, "Performatividad, prácticas corporales"; Moreno y Torres, "Performatividad" (en prensa).

${ }^{7}$ Entre los autores más importantes que han revisado el problema del deporte en el contexto del género y la masculinidad, particularmente orientados al estudio del boxeo, están: de Garis, "Be a Buddy"; Downing, "The Gentleman Boxer"; Hargreaves, "Sporting Females"; Lafferty y McKay, "Suffragettes in Satin"; Wacquant, "The Social Logic”; Woodward, "Boxing Masculinity”. Para una perspectiva sociológica sobre la vinculación entre cuerpo y deporte se puede consultar: Elias y Dunning, Deporte y ocio; Goffman, "The Arrangement”; Bourdieu, "Sport and Social Class” y “¿Cómo se puede ser deportista?”. Una mirada sociohistórica puede verse en Vigarello, "Ejercitarse, jugar"; Moreno, "La invención”. 
y representación a partir de los cuales se constituyen los discursos y las imágenes que pueblan un campo social. La relevancia para el conjunto de la vida social de los discursos e imágenes que tienen lugar en un espacio particularmente acotado - en este caso, el campo deportivo-, radica en que éste funciona como una caja de resonancia donde se produce y reproduce el orden simbólico en prácticas, metáforas y figuraciones en las que el cuerpo, pensado como un lugar privilegiado de semiosis, desempeña un papel primordial.

El boxeo, como institución deportiva específica, presenta afinidades y rupturas con el campo deportivo en general. Su enorme riqueza semiótica permite esclarecer no sólo construcciones imaginarias propias de una práctica social cuya codificación es intensiva, sino también representaciones sociales hegemónicas de la vida mundana. El foco del presente ensayo tiene que ver con las formas en que los cuerpos sexuados significan y se significan en el escenario brutal del cuadrilátero para convertir la violencia de la confrontación física - cuya finalidad expresa es la destrucción del cuerpo del otro- en una alegoría de la vida y, al mismo tiempo, en la marca semiótica por excelencia de la masculinidad.

Es decir, la producción simbólica del cuerpo del boxeador se verifica dentro de un marco de normas y valores que contiene, histórica y tradicionalmente, la función de producir masculinidad. La irresoluble aporía que representa el cuerpo de la boxeadora descuadra la maquinaria semiótica del boxeo sin interrumpir su marcha, de la misma forma en que el juego del bailarín señala este territorio con su imposibilidad para ocuparlo; no en vano, entre las disciplinas del cuerpo, la danza escénica aparece como una actividad agudamente feminizada, atribución que inclusive pone en entredicho la identidad sexual de los pocos y sobresalientes varones que se atreven a practicarlo.

No obstante esta clara separación de espacios, los mecanismos de exclusión funcionan de maneras difusas. La institución requiere un sofisticado conjunto de estrategias para admitir la presencia del sujeto que mediante su ausencia en dicha institución, la define. La admisión de las mujeres en el boxeo, por ejemplo, se convierte en un dispositivo que a la vez niega y afirma su principal enunciado en una arena social diversa y compleja. Lo que revelan esas estrategias discursivas y performáticas es el carácter difuso y cambiante de los valores de género. En lugar de tratarse de estructuras fijas, fundadas en hechos "naturales", los rasgos atribuidos a los cuerpos y sus actos en el imaginario del género (gender) son producto de interpretaciones culturales siempre en disputa y negociación. 


\section{La fuerza física en la construcción performativa de la masculinidad}

El género existe performativamente en sus encarnaciones, pero siempre en estrecha relación con interpretaciones culturales abstractas que se construyen a partir de factores muy diversos. La entronización de los significados actuales de la(s) masculinidad(es) tiene lugar en un contexto histórico determinado: el de los albores de la modernidad. Construida a partir de una tradición antigua, el símbolo que encarna el deportista a finales del siglo XIX y durante todo el siglo xx responde a una lógica que enlaza dos épocas distintas y contrastantes. Por un lado, está la figura del "caballero", representante de un ideal corporal donde se combina el uso de la fuerza bruta con la cortesía (Downing, The Gentleman Boxer). En el inicio de este proceso, hay una asociación imaginaria entre la fuerza física - como capacidad para derrotar a un adversario mediante el uso de la violencia - y la supremacía de la aristocracia medieval como clase dominante. Por el otro lado aparece la necesidad de diferenciar los papeles y los espacios sociales que constituirán las esferas de acción de mujeres y hombres como dos ámbitos incontrastables.

La lógica de la caballería, como institución fundamentalmente militar - y a la vez profundamente atravesada por elementos míticos-, supone una exaltación de la potencia corporal, de la habilidad en el manejo de las armas y de la imposición del derecho del más fuerte como el principal mecanismo de la organización social. No obstante, la modernidad necesita dulcificar y romantizar el derecho del más fuerte mediante el código de caballería, que lo postula como un instrumento de la justicia, la defensa del débil, la valentía, el honor y el refinamiento cortés. Esta vuelta de tuerca adquiere pleno sentido cuando se vuelve la base de la construcción de la masculinidad plebeya y se extiende al imaginario abstracto del "hombre", postulado por el Iluminismo como el sujeto de razón que engloba al género masculino más allá de las particularidades de clase.

De esta forma se legitima una nueva manera de leer la hombría, orientada por una cultura corporal que, durante el Renacimiento, rige la educación del caballero y del cortesano, en contraste con "la diversidad poco categorizada y exclusivamente guerrera del final de la Edad Media", para dar lugar a una concepción del mundo donde el poder de las armas deberá ceder su predominio a la vida civil. Los referentes simbólicos de este amplio desplazamiento - entre principios del siglo XVI y mediados del XVII- "de la fuerza hacia la prestancia, de la potencia hacia la destreza", estarán directamente anclados en el cuerpo, pero requerirán un programa de habilitación que permita enseñar y aprender la elegancia aristocrática, el porte, la distinción (Vigarello, "Ejercitarse, jugar" $244,246)$. 
La modernidad introduce, así, un proyecto pedagógico que se orienta a la codificación de las habilidades corporales, constitutivas del habitus de la nobleza, en una creciente conciencia de la importancia de los saberes del cuerpo. De manera por demás interesante, es precisamente en ese contexto donde aparece la danza en la corte de Luis XIV. Las cortes europeas se convertirán en espacios intensamente teatralizados para el aprendizaje de las actitudes, el dominio físico y los gestos que permiten ingresar en "la vida mundana en una sociedad de representación" (251). En Francia, en los albores de la modernidad, "el vigor corporal y su manifestación siguen siendo un signo de poder" (230); no obstante, el acento se desplaza de la expresión física de la fuerza hacia el refinamiento de la pose y la indumentaria y hacia la creación de un auténtico arte de corte para llegar a "una cultura corporal nueva de los nobles en la Francia clásica" (ibíd.). El origen de todo un rango de disciplinas - justas y torneos, juegos de lanza - está vinculado con el ethos guerrero como privilegio aristocrático. Pero este ethos se vuelve cada vez más ficticio conforme avanza el proceso civilizatorio.

De ahora en adelante, el apaciguamiento de la violencia tendrá que pasar por su morigeración mediante las instituciones que la organizan y reglamentan. De esta forma, la modernidad parece recuperar, de manera velada, una sublimación de la fuerza bruta, aunque tal legitimación - que contradice flagrantemente el ideal ilustrado de que "la fuerza no hace derecho" - requiera aún otra operación retórica: la de atribuir — siempre en el terreno de lo imaginario- el privilegio de la fuerza a los varones para privar al "sexo débil" de todo reclamo relacionado con la fuerza física.

Es aquí donde aparece la cultura boxística: en el mismo movimiento donde la identificación de la burguesía en ascenso con los valores de la aristocracia recoge la inclinación que el mundo de la corte había teatralizado sin desligarla de su origen guerrero. En el contexto del ideal ilustrado, la institucionalización del boxeo contiene la intención explícita de masculinizar a los jóvenes. Aquí se recupera el sentido de defender el propio honor con los puños como una noción tradicional de hombría, asociada, además, con una cultura que se definía mediante el combate, en una nación - la británica - que en el siglo XVIII estaba construyendo un imperio y pagando varias guerras, de modo que el Estado requería hombres capaces de portar armas y entrenados en la violencia:

El código de honor del boxeo [...] tiene vínculos con estatus de clase más elevados, por ejemplo, con la defensa personal, incluida la pelea con los puños [fist fighting] y, notablemente, las habilidades para el duelo, que eran parte del repertorio de los jóvenes caballeros en el siglo XVIII [...]. El pugilismo combina la aprobación institucionalizada del combate corporal - como un medio legítimo y moralmente aceptable de resolver disputas- con la justificación personal y la afirmación de la identidad, o más específicamente, de la masculinidad. No hay tal espacio para la afirmación de la feminidad. La 
asociación de los hombres con la guerra es un factor que contribuye a esta exclusión (Woodward 28-29). ${ }^{8}$

La reglamentación del boxeo — paso decisivo de su deportivización $-{ }^{9}$ exige la exclusión de las mujeres porque en el centro de su constitución está la necesidad de determinar las cualidades del "hombre verdadero" y la demanda de una identidad masculina apropiada y obligatoria para todas las clases sociales, asociada con la encarnación de la maestría física, la conducta caballerosa, la moral varonil y el entrenamiento del carácter. De esta forma, los deportes, en general, y el boxeo, en particular, se convierten en símbolos de la masculinidad al corporificar despliegues agresivos de poder físico y competitividad: "En el siglo XIX no había duda de que los deportes fueran el dominio 'natural' de los hombres ni de que 'ser bueno' para los deportes fuera esencialmente 'masculino"' (Hargreaves 43). La masculinidad, en este contexto, debe ser entendida como un proceso imaginario que permite crear un terreno común para "la aspiración del peleador al estatus de caballero y el deseo del caballero de ser capaz de pelear" (Downing 12-13).

\section{Fuerza / belleza}

Hay una interpretación mística del boxeo, la cual inspira una producción cultural bastante extensa - sobre todo en su versión pop - en cine, televisión, cómic, narrativa y periodismo. A partir de esta visión se elabora una figura heroica que se mueve en el mundo boxístico para fabular mitos de la modernidad, como el de la construcción de la masculinidad, la conversión del niño en hombre o la salida de la pobreza con base en el mérito individual. En todas estas expresiones, el boxeo "es conquista y destrucción, competencia pura, hombre contra hombre" (Hauser 7).

\footnotetext{
8 "Boxing's encoding of honour also carries strongly classed dimensions [...] it has links with more elevated class status, for example with self-defence, including fist fighting, and notably, duelling skills, being part of the young gentleman's repertoire in the eighteenth century [...] Pugilism combines institutionalized approval of corporeal combat as a legitimate and morally acceptable means solving disputes with personal justification and affirmation of identity, or more specifically, masculinity. There is no such space for the affirmation of femininity. The association of men with warfare is one contributory factor to this exclusion" (Woodward 28-29).

${ }^{9}$ Utilizo esta noción en el sentido en que la ha desarrollado Elias, la deportivización del boxeo transcurre por un largo proceso que lo conduce finalmente a su institucionalización y establecimiento mundial como disciplina reglamentada.
} 
En su Historia de la belleza, Georges Vigarello ubica el origen de algunos de los elementos significativos de estas mitologías en la Europa del Renacimiento. Según este autor, en ese momento crucial se inauguró una nueva concepción del género, donde se establece por primera vez la distribución universal y abstracta de cualidades femeninas y masculinas que predominará durante la modernidad. Es entonces cuando aquella "inicial belleza moderna sólo se define en femenino, combinando inevitablemente debilidad y perfección" (Vigarello 28). El cambio cultural, al tiempo que porta una valorización inédita del estatus de las mujeres, encierra la paradoja de que esa nueva apreciación "no pueda superar la oscura y reiterada certeza de una inferioridad" (ibíd.):

Un reparto se establece aquí, orientando claramente, y durante mucho tiempo, a los géneros hacia dos cualidades opuestas: la fuerza para el hombre, la belleza para la mujer; para uno "el trabajo en la ciudad y en el campo", para la otra "las tareas de la casa". [...]. La mujer sigue siendo inexorablemente "inferior", tanto más dominada en cuanto su belleza está hecha para "regocijar" al hombre o, mejor aún, para "servirlo". Creada para el otro, sigue siendo pensada para él (Vigarello, Historia de la belleza 30,34).

A partir de entonces, los temperamentos sexuales se reinterpretan de manera tal que la fragilidad -identificada ahora como "femenina" y, por lo tanto, como rasgo categórico de la condición de "mujer" - se vuelve "graciosa como nunca antes" (Vigarello 32), mientras que los varones se ven obligados a una asunción física particular, donde se subrayan la dureza, la severidad y la potencia. Esta asignación de virtudes no se generaliza de inmediato ni uniformemente, pero hacia finales del siglo XVIII está muy cerca de constituir el sentido común sobre el género.

En su origen, se trata obviamente de un atributo de clase; sin embargo, conforme la atribución se universaliza en los binarios masculino/femenino, hombre/mujer, el ideal de fragilidad empieza a funcionar en el imaginario social como una característica relacionada con la belleza "en abstracto" (a pesar de que las mujeres de las clases trabajadoras no se puedan dar el lujo de ser débiles). No obstante, en abyecta contradicción con la experiencia, la ideología de la clase dominante termina por convertirse en la ideología dominante, a partir de una investigación anatómica que estrenará una nueva manera de mirar el cuerpo:

[E]1 Iluminismo reinventó la lógica de la estética femenina y la lógica del poder masculino. El esqueleto impondría su dictado: el único destino de la mujer sería la maternidad. Esto descalifica los viejos razonamientos morales sobre la inferioridad femeni- 
na, la ternura de su temperamento, su debilidad íntima, legitimando su dependencia por la naturaleza de sus "funciones". La mujer no sabría enfrentar las cosas porque es exclusivamente responsable de engendrar y de criar a su prole. No sería capaz de participar en la vida pública para hacer prosperar mejor la infancia y la vida privada (Vigarello, Historia de la belleza 106).

La reclusión de las mujeres en el ámbito doméstico se conjugará, entonces, con esta interpretación de su potencial biológico. A partir de este momento, la heteronomía de las mujeres se explicará a partir de la constitución de su débil corporalidad, destinada al embarazo, el parto y la crianza. Y su sometimiento a los varones - en un mundo que se abría a la libre determinación individual y al reconocimiento de los demás individuos como semejantes - se justificará como la consecuencia "natural" de tal debilidad en este peculiar reducto de lo humano que queda, desde entonces, directamente relacionado con la biología, con la materia, con la animalidad. Si en el mundo moderno se postula que la fuerza no hace derecho (Serret, Identidad femenina; Laqueur, La construcción del sexo), en las relaciones entre mujeres y hombres se introduce una difícil excepción: la "superioridad natural" de los varones - manifestada como fuerza corporal, como poderío físico enfrentado a la debilidad inmanente de las hembras - legitima su dominio sobre las mujeres.

Hay una segunda consecuencia - de enorme relevancia para el tema que nos ocupade esta repartición de atributos: la interpretación de las mujeres como cuerpos destinados a la maternidad limita, desde ese momento, su capacidad de decisión. Las mujeres no pueden disponer libremente de sus cuerpos porque sus cuerpos no les pertenecen, sino que son solamente el vehículo para un fin más alto que ellas mismas: "la tendencia de la teoría inicial del contrato es hacer que la subordinación de las mujeres a los hombres sea resultado del funcionamiento de los propios hechos de la diferencia sexual, de sus implicaciones utilitarias [...]: los cuerpos no son el signo, sino el fundamento de la sociedad civil" (Laqueur 270-271)..$^{10}$

Por eso se vuelve tan perturbadora la imagen de una mujer fuerte; por eso hace falta reprimir, desnaturalizar, ocultar, ridiculizar las pretensiones deportivas de las mujeres. Y es especialmente en el boxeo donde esta divergencia se convierte en un vigoroso marcador de género. Porque el boxeo, de manera singular, recupera el valor de la fuerza bruta y lo enaltece en un nicho de exclusividad celosamente resguardado.

10 Cursivas en el original. 


\section{Cuerpo, danza, representación}

El significado del cuerpo del boxeador se ve atravesado por múltiples factores, todos ellos relacionados con la definición de la masculinidad: hay diferentes formas de expresión de la masculinidad que se reproducen en el campo específico del boxeo. Para Laurence de Garis, la masculinidad "a menudo se pone a prueba en un mundo homosocial con otros hombres" (9495). Oates habla del ataque y la sumisión absoluta del otro como reacción del ego masculino — una respuesta "que depreda la civilización" - más allá del instinto de defenderse (49).

Para Kath Woodward, las técnicas corporales y el régimen físico del entrenamiento a menudo implican "la habilidad de controlar el dolor y ejercitar la disciplina y el auto-control, los cuales operan no sólo internamente, sino que son parte de lo que constituye la masculinidad en términos temporales y espaciales" (86-87). Para Robert Anasi, un nocaut — "mandar a alguien a la lona" - significa arrebatarle la hombría (101). Para Thomas Hauser, el varón está obsesionado con la victoria (7). Para Loïc Wacquant, la cultura del gimnasio es un espacio quinta esencialmente masculino, "dentro del cual la entrada de mujeres sólo es tolerada en tanto en cuanto sea incidental" (234). Según Yvonne Lafferty y Jim McKay, los boxeadores obtienen prestigio y poder en la medida en que pertenecen al minúsculo grupo de varones que "literalmente corporifican la masculinidad hegemónica" (252). En cambio, las boxeadoras - que al exhibir agresión y fuerza "desafían los ideales de la feminidad enfatizada" - por lo general "aparecen en las peleas de relleno y gozan, para el desarrollo de su trabajo, de una pequeña fracción de los recursos que los pugilistas varones tienen garantizados" (ibíd.).

En este contexto, la masculinidad adquiere un estatuto difuso, pantanoso. Se trata de una arena de significación siempre en proceso, incapaz de establecer contenidos fijos. No obstante, existe una organización imaginaria -y por tanto derivada del orden simbólico- que estructura la producción semiótica fundamentalmente alrededor de los ejes que codifican el género.

Esa codificación es performativa. La performatividad implica dos características principales: 1) se trata de una figuración cuyo soporte material es un acto, 2) el acto es auto-referencial. Cuando hablamos de la construcción de significados en una disciplina del cuerpo, la definición del acto no está anclada exclusivamente en los enunciados lingüísticos, sino que el espacio de lo performativo abarca la corporalidad en su conjunto: movimiento, forma, ritmo, peso, color, luz, trabajo, inercia. Un acto es performativo en la medida en que es significativo/ritual y acata condiciones de validez respecto de la persona que los lleva a cabo y las circunstancias de la puesta en acto. ${ }^{11}$

11 Para reflexiones acerca de la ritualidad, el cuerpo y la performatividad puede leerse: Yébenes, "Performatividad, prácticas corporales"; Butler, "Afterword"; Demaria, "The Performative Body"; Felman, The Scandal; Markula, "Body-Movement-Change"; Pilgrim, "Performance"; Scott, "How to Look". 
Respecto de la condición de auto-referencialidad, decimos que el acto performativo tiene la propiedad de ser un acto individual, único, histórico e irrepetible: "No puede ser efectuado más que en circunstancias particulares, una vez y una sola, en una fecha y un lugar definidos [...]; es acontecimiento porque crea el acontecimiento" (Benveniste 194-195). Para Benveniste, la consecuencia de este hecho es que el significado es idéntico al referente, es decir, el acto performativo se refiere "a una realidad que él mismo constituye" (195). Decir que la masculinidad es performativa equivale a decir que se constituye a sí misma en su propia escenificación; pero, como lo ha señalado Butler (Cuerpos 34), al tiempo que se constituye, oculta o disimula las convenciones de las que es una repetición; la "magia performativa" opera en la medida en que el acto significante consigue, por un lado, delimitar y circunscribir el cuerpo, y, por el otro, postular que el cuerpo es anterior a toda significación.

A su vez, el carácter performativo del género se manifiesta en su falibilidad. En efecto, la performatividad de género adolece todas las fallas que aquejan a los actos: la posibilidad de que fracase no es accidental, "sino que el fallo forma parte constitutiva de la vida misma del performativo. Es ahí, en el fracaso, donde el performativo abre el espacio para la agencia del sujeto" (Burgos 254).

El fracaso, el fallo, la pifia, la posibilidad de cebarse, agrupados por Austin en la noción de infelicities o infortunios, ${ }^{12}$ dan cuenta, por un lado, de la enfermedad de la cual todos los actos convencionales son herederos; pero, por el otro, dan cuenta de la artificialidad del género, de la posibilidad de actuar profunda, auténticamente, la identidad "equivocada". En efecto, la capacidad performativa de representación de la masculinidad - o de la feminidad- hace residir en el acto - en la escenificación, ceremonia, ritual, performance-, y no en el cuerpo - biología, fisiología, configuración anatómica-, la condición para la verosimilitud de la identidad de género. De modo tal que un cuerpo de mujer podría representar cabalmente la masculinidad de manera tan convincente que quien la actuase tuviera la certeza de su adscripción al grupo de los varones. ${ }^{13}$

Ahora bien, también en el campo del boxeo la condición de ser único e irrepetible anida en la estructura convencional del acto codificado social y culturalmente: el significado del acontecimiento sólo tiene lugar en un marco solemne y ceremonial. Ninguno de los actos, ninguno de los gestos que componen el acto, tiene sentido fuera del contexto abigarrado y riguroso de la competencia ritual. Lo que se pone en acto no es la pura fuerza muscular, la sola habilidad corporal o el severo entrenamiento, sino el conjunto del acto boxístico en toda su complejidad.

12 Austin, J. Cómo hacer cosas con palabras. Buenos Aires: Paidós, 1971.

13 Agradezco a Rodrigo Parrini la discusión que generó estas reflexiones. 
Veamos: el campo del boxeo es performativo en tanto se trata de un espacio de institución; como explica Bourdieu (Language E Symbolic), el trabajo de institución — de institutere, institutio - implica un acto inaugural de constitución, de fundación, de invención; el cual, mediante el proceso educativo, conduce a disposiciones, hábitos o usos permanentes. En cada acto de institución hay una minuciosa repartición de lugares, tareas, funciones, autoridades. ${ }^{14}$ Repartición codificada de manera puntual mediante signos (actos) visibles, unívocos, convencionales: un lugar para cada actor y cada actor en su lugar, cada uno ataviado con la vestimenta que le corresponde - en obediencia de una estricta etiqueta - y dispuesto a recitar en el instante preciso las líneas que le corresponden en el script general. La arena organiza la acción en tanto distingue con claridad impecable la función del espacio en cada uno de sus puntos: desde los vestidores hasta las gradas, desde la sala de prensa hasta las taquillas, desde los corredores por donde pasarán los contrincantes hasta las filas reservadas para los espectadores VIP, ostentosamente engalanados.

El cuadrilátero es un escenario que permite, dentro de la inmensa gama posible de la expresión corporal, un rango limitado de acciones. Cada acción tiene un significado y está asociada con un actor autorizado y una serie de condiciones de autenticidad. La validez de los actos queda anotada en los registros oficiales. El performativo puro de la declaración de triunfo - "el ganador de esta pelea..."- está inmerso en una intrincada puesta en escena donde no se logran identificar factores insignificantes.

El tiempo del boxeo es uno de los marcos materiales más significativos del acto. El calendario, el horario, la programación, las decisiones que categorizan los encuentros "de relleno" respecto de la pelea principal, planifican el encuentro en el tiempo grueso de los días y las horas. Seguidos por reflectores, los contendientes atraviesan el largo camino entre los vestidores y el cuadrilátero en medio del griterío de la afición y los flashes de las cámaras fotográficas. No hay aficionados imparciales; el campo es maniqueo: blanco o negro, azul o rojo, bien o mal:

Ahí es donde está la gran exaltación de la razón en el boxeo. Quienes defendemos o hemos defendido el boxeo en algún momento llevamos la idea de la ficción a la idea de que, si se confrontan dos cuerpos potencialmente idénticos, la supremacía es en realidad la gran realización estratégica. El box es el triunfo de la razón estratégica, la gran visibilidad de la razón estratégica [...]: en el box se da el encuentro de las

14 "La eficacia mágica de estos actos de institución [los enunciados performativos] es inseparable de la existencia de una institución que defina las condiciones [...] que deben reunirse para que la magia de las palabras pueda actuar" (Bourdieu, ¿Qué significa hablar? 46). 
potencias puras en confrontación. Las potencias puras en una condición de equiparación cuya única posibilidad de resolución es la supremacía estratégica (Mier, entrevista). ${ }^{15}$

Desde el momento de su aparición, el combatiente danza. Cubierta la cabeza por la capucha de su bata, acompañado de su equipo, rodeado por una corte de fanáticos y periodistas, el boxeador trota, mueve el cuello, levanta los hombros, muestra los puños, saluda al público con la mano en alto. Finalmente, sube al cuadrilátero haciendo gala de agilidad y deja atrás a la muchedumbre anónima. Cada movimiento está codificado; sólo los boxeadores se mueven así; dentro de ese marco, ninguna otra persona está autorizada a hacerlo. ${ }^{16}$

En el centro de la arena se levanta el cuadrilátero, foco de todas las miradas. El escenario está profusamente iluminado, mientras que el graderío permanece en penumbra. En la preparación del combate sólo participan el presentador, el réferi y los propios peleadores, cada uno acompañado de su mánager y uno o dos seconds. El ring es significativamente territorial: dos de las esquinas son neutrales y cada una de las restantes pertenece a un contendiente. El inicio es confuso y aparentemente desordenado. Los peleadores transitan del banquillo al centro del ring, cuidándose quizá de no invadir aún la circunscripción del enemigo.

Mánagers y seconds administran su parafernalia: una cubeta, un botiquín, una toalla. Masajean los pectorales y los gemelos del boxeador. Le susurran frases al oído. El peleador mira al adversario en actitud retadora y sigue danzando mientras el réferi inspecciona el vendaje y los guantes. La pelea ha empezado semanas, quizá meses antes de la fecha de su verificación, desde el momento de su anuncio, de manera relevante en la ceremonia de pesaje. Los rivales se han visto, se han medido con la mirada, se han seguido en los medios. Ahora se encontrarán, en efecto. Exactamente antes de comenzar el combate, se miran y actúan su desprecio mutuo.

$\mathrm{Al}$ ascenso de los boxeadores pueden seguir innumerables rituales dilatorios. El boxeo es un encuentro de dos cuerpos desnudos que se regocija en el foreplay. El anunciador toma el micrófono e invita a las celebridades a compartir el escenario. Suben al ring los famosos - ex boxeadores, actrices, políticos- y la gente que se inviste performativamente de la fama de los peleadores. La prensa toma nota, toma fotos, constantemente irrumpe en el acto y es desalojada.

15 Entrevista personal realizada por Hortensia Moreno, en la Universidad Autónoma Metropolitana, plantel Xochimilco.

16 Obviamente, la mímica del boxeo es reproducida de manera intensa por los cuerpos adolescentes y juveniles de los muchachos de barrio, de quienes reclaman para sí la masculinidad ejemplar del boxeador. 
Por fin, el combate va a empezar. Todos los extraños se ven obligados a abandonar la pista. El anunciador, con sus papeles en la mano, grita al micrófono el nombre del campeón, que es calurosamente ovacionado por el respetable. Enuncia sus títulos, su peso, la división en que se ubica. Grita después el nombre del retador y lo mismo. “Pelearáaaaan...!” - e indica ahora la duración del encuentro-.

Mientras tanto, los boxeadores danzan. Ya se han quitado las batas, se han calzado los guantes, se han metido a la boca los protectores y exhiben sus cuerpos perfectos y sus calzoncillos más o menos elaborados. No hay mucho juego para la extravagancia en el boxeo; los extravagantes siempre son juzgados con desaprobación. En cuestión de segundos desaparecen todos los objetos del equipo de apoyo. En el cuadrilátero quedan solamente tres personas.

El cronómetro estructura el tiempo fino de los asaltos en la marca rigurosa del sonido de la campana. Durante el tiempo de cada round, sólo pueden estar en el ring los contendientes y el réferi. Las indumentarias tienen que ser cuidadosamente distintivas: es notable el contraste entre los pechos desnudos y la corrección de la camisa y la corbata del árbitro. La danza se complica. De ser un movimiento solitario se convierte en una frecuentación concertada, un cálculo del cuerpo del otro a partir del alcance del brazo o la precisión del tranco. Nadie está más concentrado en el cuerpo de otro que el boxeador a punto de conectar un golpe.

El cuerpo rigurosamente preparado durante meses, años, décadas. El cuerpo superpuesto a todos los cuerpos que en el cuadrilátero han sido. El cuerpo que hace sombra frente a su espejo. El espejo de ese cuerpo, de pronto indistinguible del cuerpo del otro. El cuerpo trenzado en el clinch. El cuerpo castigado al recibir el primer golpe y al escuchar, como en sueños, la reacción de la multitud enardecida, lentamente preparada, predispuesta, activa y feroz. Cada golpe-acontecimiento auto-referencial, performativo, único e irrepetible. Acto puro, acto desnudo y sin embargo anclado en la maraña de los signos. Signo y referente de sí mismo. Representación ritual, ceremonia colectiva. Creación y destrucción simultánea de corporalidades en el esfuerzo por encontrar el sentido de la vida.

El sentido de la vida del boxeador, el sentido del grupo cerrado del equipo de apoyo o de la familia; o bien del grupo abierto del barrio, de la nación o la humanidad. El cuerpo del boxeador se entrega al público sediento de acción. El dictamen escrupuloso de los jueces, el abucheo de la afición, la advertencia de las manos del réferi que lleva la cuenta implacable de los segundos fuera (de ese tiempo suspendido durante el cual el peleador se sume en una presencia ausente, en una conciencia turbia). El cuerpo del vencedor y el cuerpo del vencido son uno solo; el cuerpo se cubre de gloria en el combate: el rostro congestionado, los brazos adoloridos, el olor del sudor mezclado con la sangre que mana de las heridas y los orificios. 


\section{El cuerpo de la boxeadora}

El marco de normas y valores donde se desenvuelve el cuerpo de la boxeadora persiste en su hipermasculinidad. Las estrategias que el campo social del boxeo debe desarrollar para que las mujeres suban al cuadrilátero, incluyen un dispositivo que a la vez niega y afirma su principal enunciado: el de que se trata de una actividad cuyo fin principal es la producción de la hombría. El cuerpo de la boxeadora se desenvuelve en el mismo contexto simbólico, pero está marcado por una característica diferencial que le da al segundo el fundamento de su consistencia semiótica. ${ }^{17}$

En principio, el fenómeno es estrictamente discursivo-lingüístico: se trata de un resorte de significación mediante el cual queda marcado el cuerpo del Otro para establecer la representación del Uno. El cuerpo del boxeador, en tanto dispositivo significante, se refiere al cuerpo de la boxeadora como el elemento marcado. La marca funciona como signo de reconocimiento, es decir, como "operación cognoscitiva por la que un sujeto establece una relación de identidad entre dos elementos, de los cuales uno está presente y el otro ausente" (Greimas y Courtés 253-254). ${ }^{18}$ La oposición "marcado/no marcado" se emplea para distinguir dos elementos de significación "según que estén caracterizados por la presencia o la ausencia de un rasgo distintivo" (Greimas y Courtés 332). En los procesos de identidad, ciertos rasgos distintivos se constituyen en "marcas" cuando señalan a un sujeto como "otredad".

De manera paradójica, aquí el término no-marcado (el cuerpo del boxeador), se constituye al mismo tiempo como un lugar normativo - carente de atributos - y como la encarnación del mandato cultural e institucional ante el cual los cuerpos no entrenados de los varones comunes y corrientes figurarían como excluidos. No obstante, la magia performativa del boxeo permite a los cuerpos no entrenados de los varones compartir con el atleta la condición del "hombre" como universal, pero sólo en la medida en que contiene la exclusión del otro concreto (la mujer) que encarna su exterior constitutivo.

Las marcas por excelencia de la otredad identitaria señalan performativamente a los cuerpos que proporcionan el marco de inteligibilidad de quienes se postulan como sujetos en sentido pleno. Las oposiciones funcionan al contrastar ciertos rasgos "biológicos" como

17 He profundizado sobre la situación de las mujeres en el campo social del boxeo en Moreno, "Mujeres"; "Boxeo, peligro, masculinidad"; Orden discursivo; "La noción"; "El boxeo"; "Boxeuses à Mexico"; "Women boxers"; "Género, nacionalismo" y "Capital social".

18 "Esta discusión general de los límites del espacio y del tiempo implica otra serie de equivalencias metafóricas fundamentales [...] normal/anormal::temporal/intemporal::categorías bien delimitadas/categorías ambiguas::central/marginal::profano/sagrado" (Leach 47). 
indicadores "naturales" de diferencia. De esta forma, se construyen oposiciones donde, por ejemplo, el color de la piel se convierte en un marcador que permite, a quienes se presentan como "blancos", representar su identidad como una ausencia de atributos. De tal modo que es la otredad y sólo la otredad la que está marcada, mientras que la ausencia de marca se postula como el principio normativo de la oposición. Lo que se juega aquí es "un régimen disciplinario que genera, forma y construye discursivamente al sujeto"; se trata de modelos de discurso normativos e idealizados que producen, o traen al ser, a los propios sujetos que supuestamente demarcan (Ehlers 17-18).

Un límite separa dos zonas del espacio-tiempo social normales, temporales, bien delimitadas, centrales, profanas; pero los marcadores espaciales y temporales que realmente sirven de límites son también anormales, intemporales, ambiguos, marginales, sagrados [...]. Siempre que distinguimos categorías dentro de un campo unificado, espacial o temporal, lo que importa son los límites; concentramos nuestra atención en las diferencias, no en las semejanzas, y esto nos hace creer que los marcadores de tales límites son de valor especial, "sagrado", "tabú" [...]. El cruce de fronteras y umbrales siempre se rodea de ritual; también, por lo tanto, el cambio de un estatus social a otro (Leach 48). ${ }^{19}$

¿Qué hace el cuerpo de la boxeadora? Por una parte, repite cada uno de los gestos, cada una de las acciones que constituyen el gran ritual. Pero la repetición está signada por una diferencia que la sitúa en un espacio de liminalidad. Está atravesando un umbral y está a punto de adscribirse de manera simbólica a un estatuto que le está vedado. Su condición excepcional la sitúa entre aquellas figuras que Françoise Héritier-Augé ("Mujeres ancianas") caracteriza como "mujeres con corazón de hombre": atraviesa las fronteras femenino-masculino y al hacerlo revela la índole porosa y flexible de estas fronteras.

No obstante, el campo restablece sus reglas y recupera performativamente la distinción: las boxeadoras, cuerpos activos en el campo deportivo, son también danzantes y representantes; pero su signo es el de la feminidad enfatizada: por más rudas y fuertes que puedan aparecer en el escenario del ring, su apuesta se deslizará hacia la reivindicación de la delicadeza, la gracia, los buenos modales, el cuidado indumentario y la discreción. Entre los cuerpos de las deportistas, quizá no haya cuerpo más femenino que el cuerpo de la boxeadora.

19 Cursivas en el original. 


\section{Conclusiones}

En la medida en que los deportes se utilizan como expresión de la "naturaleza masculina" - como un arreglo diseñado para que los varones manifiesten cualidades masculinas-, tienen una función doble: por un lado, representar, poner en acto, servir como escenario para el performance de la "obvia" diferencia biológica - la cual se traduce irremediablemente en la inferioridad corporal de las mujeres-, y por el otro aportar el marco social que permite el desarrollo de dos culturas complementarias y paralelas que anclan los procesos de diferenciación sexual en usos diferenciales del cuerpo y la actividad física. Tales culturas crean las condiciones para la producción material de cuerpos que cultivan y realzan la diferencia corporal como destino. ${ }^{20}$

Dicho postulado de "naturaleza" oculta, por un lado, los mecanismos y tecnologías que permiten a una persona en particular convertirse en la portadora de una corporalidad atlética: iniciación oportuna, adecuación a la disciplina, entrenamiento riguroso, alimentación óptima, más todos los factores - sociales, políticos, económicos, geográficos, ecológicos, familiares, subjetivos, comunicativos- que sostienen esa conversión. ${ }^{21}$ Por el otro lado, oculta también la condición contingente de la corporalidad humana, su fragilidad inherente, el hecho de que todo cuerpo está sujeto a procesos de renovación y deterioro que son inevitables (nacer, crecer, enfermar, sanar, deprimirse, alegrarse, engordar, adelgazar, agotarse, recuperarse, envejecer, morir, etc.); así como a sucesos accidentales sobre los que no tenemos ningún control (choques, intoxicaciones, caídas, estallidos, cortaduras, colisiones, sismos, incendios, tropiezos, ataques, asaltos, envenenamientos). La vida está llena de percances que inciden de manera sustantiva en el cuerpo y van configurando sus alcances, sus capacidades, sus potencialidades.

\section{Referencias}

Anasi, Robert. The Gloves: A Boxing Chronicle. Nueva York: North Point Press, 2002. Austin, John. Cómo hacer cosas con palabras. Buenos Aires: Paidós, 1971. Benveniste, Émile. "La filosofía analítica y el lenguaje". Problemas de lingüistica general. México: Siglo XXI, 1976, pp. 188-197.

20 "Como consecuencia de este entrenamiento temprano en los deportes, los individuos pueden acarrear a lo largo de la vida un marco de disposición y respuesta, un sistema de referencia que aporta evidencia, quizá la evidencia, de que poseemos cierta naturaleza" (Goffman 322). Cursivas en el original.

${ }^{21}$ En otra parte (Moreno, "La invención") he discutido la invención del cuerpo atlético. 
Bourdieu, Pierre. ¿Qué significa hablar?: Economía de los intercambios lingüísticos. Madrid: Akal Ediciones, 1999.

Bourdieu, Pierre. Language E Symbolic Power. Ed. John B. Thompson. Cambridge: Harvard University Press, 1991.

Bourdieu, Pierre. “¿Cómo se puede ser deportista?” Sociología y cultura. México: Conaculta/Grijalbo, 1990, pp. 193-213.

Bourdieu, Pierre. "Sport and Social Class". Social Science Information, vol. 17, núm. 6, 1978, pp. 819-840.

Burgos Díaz, Elvira. Qué cuenta como una vida: La pregunta por la libertad en Judith Butler. Madrid: A. Machado Libros, 2008.

Butler, Judith. "Afterword". The Scandal of Speaking Body: Don Juan with J. L. Austin, or Seduction in Two Languages, Shoshana Felman. Stanford: The Stanford University Press, 2003.

Butler, Judith. Cuerpos que importan. Sobre los limites materiales y discursivos del "sexo". Buenos Aires: Paidós, 2002.

Camacho Quintos, Patricia. Danza y box: bálsamo y herida. México: Instituto Nacional de Bellas Artes, 2007.

De Garis, Laurence. "Be a Buddy to Your Body': Male Identity, Aggression, and Intimacy in a Boxing Gym". Masculinities, Gender Relations and Sport, Jim McKay, et al. Thousand Oaks, Londres y Nueva Delhi: Sage Publications Inc., 2000, pp. 87-107.

Demaria, Cristina. "The Performative Body of Marina Abramović Rerelating (in) Time and Space”. European Journal of Women's Studies, vol. 11, núm. 3, 2004, pp. 295-307.

Downing, Karen. 2010. “The Gentleman Boxer: Boxing, Manners, and Masculinity in Eighteenth-Century England". Men and Masculinities, vol. 12, núm. 3, pp. 1-25.

Ehlers, Nadine. Racial Imperatives: Discipline, Performativity, and Struggles against Subjection. Bloomington e Indianapolis: Indiana University Press, 2012.

Elias, Norbert. "La génesis del deporte como problema sociológico". Deporte y ocio en el proceso de la civilización, Norbert Elias y Eric Dunning. México: Fondo de Cultura Económica, 1995, pp. 183-211.

Felman, Shoshana. The Scandal of Speaking Body: Don Juan with J. L. Austin, or Seduction in Two Languages. Stanford: The Stanford University Press, 2003.

Godínez, Gloria. Conversación electrónica con Hortensia Moreno. 8 de marzo de 2018. Transcripción de mensaje de texto.

Goffman, Erving. "The Arrangement between the Sexes". Theory and Society, vol. 4, núm. 3, 1977, pp. 301-331.

Greimas, Algirdas, y Joseph Courtés. Semiótica: diccionario razonado de la teoría del lenguaje. Madrid: Gredos, 1982. 
Hargreaves, Jennifer. Sporting Females: Critical Issues in the History and Sociology of Women's Sports. Londres y Nueva York: Routledge, 1994.

Hauser, Thomas. The Black Lights: Inside the World of Professional Boxing. Fayetteville: The University of Arkansas Press, 2000.

Héritier-Augé, Françoise. "Mujeres ancianas, mujeres de corazón de hombre, mujeres de peso". Fragmentos para una historia del cuerpo humano. Comps. Michel Feher, Ramona Naddaf y Nadia Tazi, tomo 3. Madrid: Taurus, 1990, pp. 280-298.

Hollywood, Amy. "Performativity, Citationality, Ritualization". Bodily Citations: Religion and Judith Butler. Comps. Ellen T. Armour y Susan M. St. Ville. Nueva York: Columbia University Press, 2006, pp. 251-266.

Lafferty, Yvonne, y Jim McKay. 'Suffragettes in Satin Shorts'? Gender and Competitive Boxing". Qualitative Sociology, vol. 27, núm. 3, 2004, pp. 249-276.

Laqueur, Thomas. La construcción del sexo. Cuerpo y género desde los griegos hasta Freud. Madrid: Ediciones Cátedra/Universitat de València/Instituto de la Mujer, 1994.

Leach, Edmund. Cultura y comunicación. La lógica de la conexión de los símbolos. Madrid: Siglo XXI, 1989.

Markula, Pirkko. "Body-Movement-Change: Dance as Performative Qualitative Research". Journal of Sport E Social Issues, vol. 30, núm. 4, 2006, pp. 353-363.

Mier, Raymundo. Entrevista personal con Hortensia MoreNúm. 13 de enero de 2006. Transcripción.

Moreno, Hortensia y César Torres. "Performatividad". Conceptos clave en los estudios de género. Coord. Hortensia Moreno y Eva Alcántara, volumen II. México: Centro de Investigaciones y Estudios de Género de la UNAM, en prensa.

Moreno, Hortensia. "La noción de capital social en el estudio del boxeo femenil en la Ciudad de México”. GénEros, vol. 22, núm. 17, 2015, pp. 51-74.

Moreno, Hortensia. "Women Boxers and Nationalism in Mexico". Sports and Nationalism in Latin/o America. Eds. Héctor Fernández L'Hoeste, et al. New York: Palgrave Macmillan, 2015, pp. 181-200.

Moreno, Hortensia. “Género, nacionalismo y boxeo". Identidad imaginaria: sexo, género y deseo. Coord. Estela Serret. México: Universidad Autónoma Metropolitana-Azcapotzalco, 2015, pp. 255-291.

Moreno, Hortensia. "La invención del cuerpo atlético". AIBR. Revista de Antropología Iberoamericana, vol. 8, núm. 1, 2013. pp. 49-82.

Moreno, Hortensia. "Boxeuses à Mexico: Corps, violence et genre”. Problemes d'Amérique Latine, núm. 84, 2012, pp. 95-112.

Moreno, Hortensia. Orden discursivo y tecnologías de género en el boxeo. México: Inmujeres, 2011. 
Moreno, Hortensia. "La noción de 'tecnologías de género' como herramienta conceptual en el estudio del deporte", Punto Género, núm. 1, 2011, pp. 41-62.

Moreno, Hortensia. "El boxeo como tecnología de la masculinidad". La ventana. Revista de estudios de género, vol. IV, núm. 33, 2011, pp. 152-196.

Moreno, Hortensia. “Boxeo, peligro, masculinidad”. Revista de Investigación Social, año v, núm. 8, 2009, pp. 41-59.

Moreno, Hortensia. "Mujeres en el cuadrilátero: la dialéctica del 'fuera de lugar". Los contornos del alma y los límites del cuerpo: género, corporalidad y subjetivación. Coord. Rodrigo Parrini Roses. México, Programa Universitario de Estudios de Género de la UNAM, 2007, pp. 79-99.

Oates, Joyce Carol. 2002. On Boxing. Nueva York: Ecco (Harper Collins).

Palma Hernández, Erendira. "Un boxeador necesita ser un buen bailarín, dice el entrenador cubano Miguel Baro”. La Jornada, 18 de mayo de 2013, p. A15, en línea. Consultado el 18 de enero de 2018.

Pilgrim, Anita Naoko. "Performance and the Performative". Body E Society, vol. 7, núm. 4, 2001, pp. 87-96.

Prieto Stambaugh, Antonio. "En torno a los estudios del performance, la teatralidad y más". Performancelogía, 2002, en línea. Consultado el 28 de enero de 2018.

Prieto Stambaugh, Antonio. “iLucha libre! Actuaciones de teatralidad y performance”. Actualidad de las artes escénicas. Perspectiva latinoamericana. Comp. Domingo Adame. Xalapa: Universidad Veracruzana, 2009, pp. 116-143.

Salomón, Alfredo, director. Round en la sombra. México: Santas Producciones / Consejo Nacional para la Cultura y las Artes / Fondo Nacional para la Cultura y las Artes, 2007.

Schechner, Richard. Performance Studies: An Introduction. Londres y Nueva York: Routledge, 2002.

Scott, Susie. "How to Look Good (Nearly) Naked: The Performative Regulation of the Swimmer's Body". Body \& Society, vol. 16, núm. 2, 2010, pp. 143-168.

Slaughter, Stephany y Hortensia Moreno, coords. Representación y fronteras: el performance en los límites del género. México: Programa Universitario de Estudios de Género de la UnAM / Fondo de Desarrollo de las Naciones Unidas para la Mujer, UNIFEM, 2009.

Serret, Estela. Identidad femenina y proyecto ético. México: Miguel Ángel Porrúa / Programa Universitario de Estudios de Género de la UNAM / Universidad Autónoma Metropolitana Azcapotzalco, 2002.

Turner, Victor. The Anthropology of Performance. Nueva York: PAJ Publications, 1988.

Vigarello, Georges. "Ejercitarse, jugar". Historia del cuerpo: del Renacimiento a la Ilustración. Alain Corbin, et al. vol. 1. Madrid: Taurus, 2005, pp. 229-292. 
INVESTIGACIÓNTEATRAL

Revista de artes escénicas y performatividad

Vol. 9, Núm. 13

abril-septiembre 2018
El cuerpo del/la boxeador/a:

danza y representación

Hortensia Moreno

Vigarello, Georges. Historia de la belleza. El cuerpo y el arte de embellecer desde el Renacimiento hasta nuestros días. Buenos Aires: Nueva Visión, 2005.

Wacquant, Loïc. "The Social Logic of Boxing in Black Chicago: Toward a Sociology of Pugilism". Sociology of Sport Journal, vol. 9, 1992, pp. 221-254.

Woodward, Kath. Boxing, Masculinity and Identity: The "I" of the Tiger. Londres y Nueva York: Routledge, 2007.

Yébenes Escardó, Zenia. 2015. "Performatividad, prácticas corporales y procesos de subjetivación”. Diario de campo, núms. 6-7, 2015, pp. 70-74.

\section{Ficha técnica de Round en la sombra (video)}

\begin{tabular}{|l|}
\hline País: México. \\
\hline Año: 2007. \\
\hline Duración: 12 minutos 23 segundos. \\
\hline Dirección y postproducción: Alfredo Salomón. \\
\hline Producción: Elsa Castillo. \\
\hline Fotografía y edición: Andrés Castañeda. \\
\hline Sonido y música: Alejandro Arce. \\
\hline Asistente de foto: Alejandro Coronado. \\
\hline Asistente de producción: Gabriela Loaria. \\
\hline Voz en off: Fidel Romero. \\
\hline $\begin{array}{l}\text { Actuación: bailarín, Gilberto González; boxeador, Dante Jardón; alter ego, Ricardo “Fini- } \\
\text { to” López; réferi, Enrique Morales; modelo, Viviana Bravo. }\end{array}$ \\
\hline $\begin{array}{l}\text { Maquillaje proestético: Jorge Díaz y Jessica González; maquillaje: Ángeles Luna; ilumina- } \\
\text { dor: Jesús Fuentes (Canal 22). }\end{array}$ \\
\hline Asistente de iluminación: Gabriel González y Porfirio Galicia \\
\hline Responsable de audio: Francisco Puga \\
\hline Montaje: Francisco Borgia y Julio Velázquez. \\
\hline Video completo en: https://vimeo.com/234105 [consultado el 3 de junio de 2017]. \\
\hline
\end{tabular}

